\title{
The impacts of permanent irradiation on the terrestrial ecosystems of the Eastern-Ural Radioactive Trace
}

\author{
I.V. Molchanova, V.N. Pozolotina, E.V. Antonova and L.N. Mikhaylovskaya \\ Institute of Plant and Animal Ecology, Ural Division of Russian Academy of Sciences, \\ Yekaterinburg, Russian Federation
}

\begin{abstract}
The complex radioecological investigations of the East-Ural Radioactive Trace were conducted. Three transects were established in EURT area: central, eastern and western. The current levels of soil contamination near the epicenter of the accident reach $30 \times 10^{3} \mathrm{kBq} / \mathrm{m}^{2}$ for ${ }^{90} \mathrm{Sr}$ and $1 \times 10^{3} \mathrm{kBq} / \mathrm{m}^{2}$ for ${ }^{137} \mathrm{Cs}$. Contamination levels are reduced in accordance with a power function with increasing distance from the accident site and at a distance of more than $100 \mathrm{~km}$ become close to background values. In the EURT impact area vegetation is a complex of synanthropic and semi-natural plant communities in various stages of degradation and restoration successions. The current state of phytocenosises on the sites of the demolished local villages is largely determined by the degree of human impact in the pre-accident period, and remediation activities. For most species the viability of their seed progeny, formed in a gradient of radioactive contamination, are either not different from background samples or reduced half a century after the accident. Mutability of seed progeny in impact coenopopulations in all studied species was high. Radioadaptation phenomenon, i.e. increased resistance to provocative irradiation is rare and unstable.
\end{abstract}

\section{INTRODUCTION}

In 1957, about $74 \mathrm{PBq}$ radioactive substances were emitted into the atmosphere as a result of radiation accident at the Mayak Production Association [1]. The vast territory $\left(23,000 \mathrm{~km}^{2}\right)$ of the Russian Federation has been contaminated. This zone was later recognized as the East-Ural Radioactive Trace (EURT). In accidental emissions ${ }^{90} \mathrm{Sr}$ prevailed among the long-lived radionuclides. In 1967, the same area was subjected to a secondary contamination resulting from radioactive sediments transport by wind from Mayak technological reservoir, Lake Karachay. The main contaminant in this case was ${ }^{137} \mathrm{Cs}$; increased radionuclide contents in the environment pose a potential danger to the biota. The presented work was dedicated to study the patterns of spatial distribution of ${ }^{90} \mathrm{Sr}$ and ${ }^{137} \mathrm{Cs}$ in soil and vegetation EURT and evaluation of effects of chronic exposure to a plant population.

\section{MATERIALS AND METHODS}

During long-term research, three transects were established in EURT area, $110 \mathrm{~km}$ each: 1) central, 2) eastern and 3) western [2,3]. Within transects soil profile samplings were done at different distances from the epicenter of the accident. The samples were taken to a depth of $50 \mathrm{~cm}$. The total content of radionuclides in this layer was normalized to the area (recognized as the store). The above ground mass of different species of herbaceous plants was cut near the soil profiles. The content of ${ }^{90} \mathrm{Sr}$ in soil and plant samples was determined through radiochemical method, and ${ }^{137} \mathrm{Cs}$ through a gamma-spectrometer with a semiconductor detector. The procedural error did not exceed $20 \%$. For a correct assessment of radionuclides in samples collected in different years, we applied the correction for the radioactive decay.

In our geo-botanical studies we used the species abundance scale developed by O. Drude and Raunkier classification. Biological effects of chronic exposure were studied in the seed progeny of 11 plant species. Seed germination was carried out in the roll culture in conditions of constant 


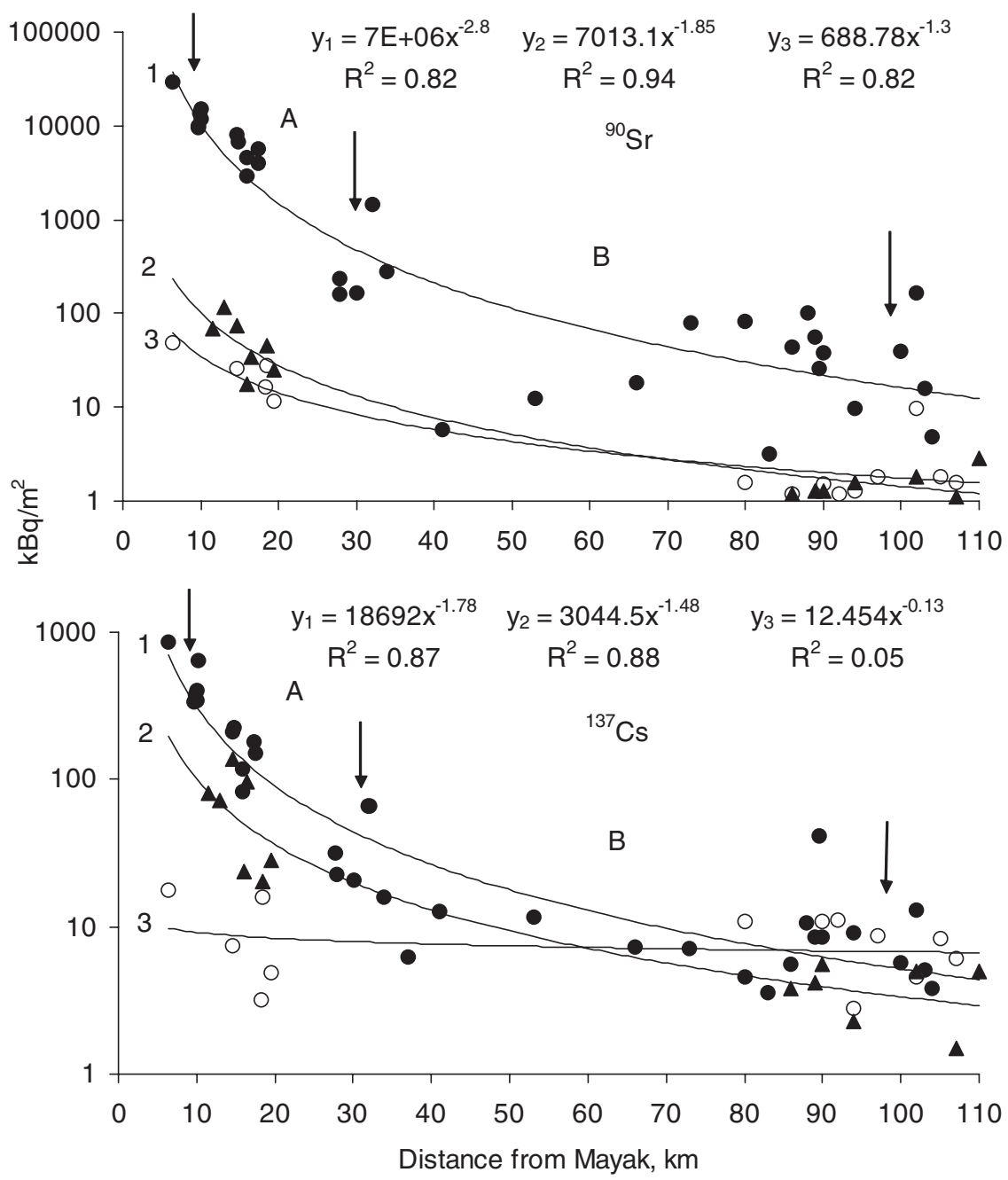

Figure 1. Store of radionuclides in EURT soils. Area: A - impact, B - buffer; transects: 1 - central, 2 - eastern, 3 - western.

temperature and 12-hour daylight. Viability was assessed by seed germination energy and germination, seedling survival, root length, rate of formation of true leaves. Mutability was recorded by frequency of occurrence in morphose samples. Radiosensitivity of the seed progeny were determined based on the same set of criteria, conducting pre-irradiation of seeds in varied doses.

\section{RESULTS AND DISCUSSIONS}

The area was divided into impact and buffer zones by the contents of the main contaminants in the EURT soil cover. The impact area is $30 \mathrm{~km}$ off the epicenter of the accident. The buffer area adjoined the impact one and was characterized by decline in ${ }^{90} \mathrm{Sr}$ contamination gradient to the background level, which totals $1.0-1.5 \mathrm{kBq} / \mathrm{m}^{2}$ in the Urals region. Its maximum store reaches $30 \times 10^{3} \mathrm{kBq} / \mathrm{m}^{2}$. In the buffer area, gradual decrease in radionuclide store in soil is observed (Fig. 1). We recorded also a decreased store of ${ }^{90} \mathrm{Sr}$ in soil cover within transition from the central axis to the periphery of the trace. In all cases, the change in the content of radionuclide in soil as the distance increases can be approximated 


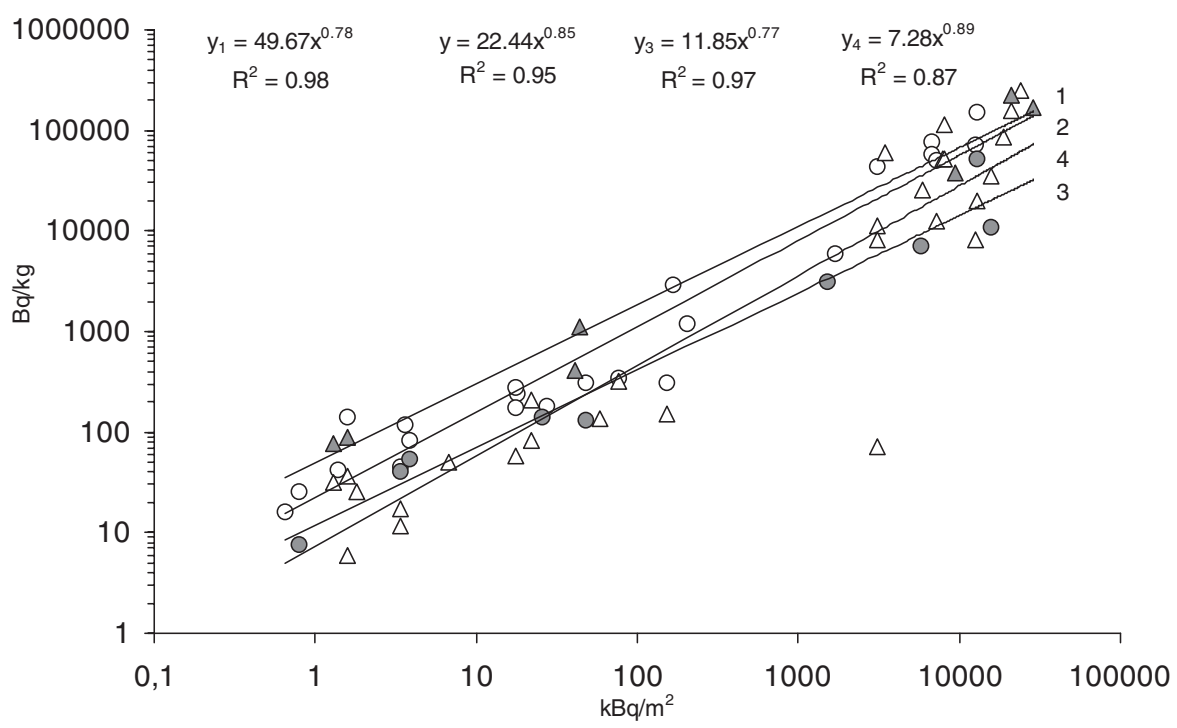

Figure 2. The specific activity of ${ }^{90} \mathrm{Sr}$ in plants subject to its store in soils. Families: $\triangle 1-$ Rosaceae, $\bigcirc 2-$ Urticaceae, $\bigcirc 3$ - Poligonaceae, $\triangle 4$ - Asteraceae.

by power functions with a high degree of reliability. The same dependence was recorded for contents of ${ }^{137} \mathrm{Cs}$ in soils of central and eastern sections of the trace. At the same time the content of ${ }^{137} \mathrm{Cs}$ in the western section is almost independent of the distance and held at $5-10 \mathrm{kBq} / \mathrm{m}^{2}$, which is close to the average background values characteristic for the Urals region. The eastern transect is contaminated by ${ }^{137} \mathrm{Cs}$ to a greater extent than the western one. Additional amounts of this nuclide could enter the soil cover in the eastern section due to the wind transport of sediments from coastal the lake Karachay [1].

Levels of soil contamination are reflected in the accumulation of radionuclides in various plant species. Analysis of the material obtained revealed no fundamental differences between species in accumulation of radionuclides. For this reason Fig. 2 shows data on species grouped into four families. The specific activity of ${ }^{90} \mathrm{Sr}$ in the aboveground mass of plants pertaining to different families subject to soil contamination is approximated by a power function with a high degree of reliability. The same dependence, but expressed less clearly, was observed for ${ }^{137} \mathrm{Cs}$.

For all species studied there is a high variability of transfer factors (TF - the ratio of specific activity of above-ground plant mass, $\mathrm{Bq} / \mathrm{kg}$ for soil contamination density, $\mathrm{kBq} / \mathrm{m}^{2}$ ) subject to both species characteristics and conditions for plant growth (Table 1). Previously, it was observed a high diversity of TF values for plants of one species, growing within a single population $[4,5]$. Our analysis showed that plants growing in the contaminated zone usually accumulate radionuclides to a lesser extent than in the background area. Comparison of these samples by Student's test showed highly significant differences (for ${ }^{90} \mathrm{Sr} \mathrm{t}_{\text {exp. }}=44.2$; for ${ }^{137} \mathrm{Cs} \mathrm{t}_{\text {exp. }}=8.6$ with $\mathrm{t}_{\text {table }}=2.83$ and $p=0.05$ ). In all cases, accumulation ability of plants for ${ }^{90} \mathrm{Sr}$ by $1-2$ orders of magnitude greater than for ${ }^{137} \mathrm{Cs}$ [2].

Vegetation at the impact zone of EURT is a complex of synanthropic and semi-natural communities at various stages of degradation and restoration successions. It is represented by birch and mixed forests, steppe herbaceous communities, and aspen groves, located in the relief depressions. Prior to the accident there were small settlements, fields and meadows in the area. After the accident occurred the arable lands have been abandoned due to the area contamination, and they developed temporary plant communities, which are stages in the process of restoring natural vegetation. Currently, most of the fallow land in the EURT area went through the stage of initial phytocenosises that precedes the formation of young forest and steppe (depending on soil type). In meadow and forest coenosises, reduced portion of ruderal 
Table 1. Transfer factors (TF) of radionuclides in plants in EURT area.

\begin{tabular}{|l|c|c|c|c|c|c|}
\hline \multirow{2}{*}{ Species } & \multicolumn{3}{|c|}{${ }^{90} \mathrm{Sr}$} & \multicolumn{3}{c|}{${ }^{137} \mathrm{Cs}$} \\
\cline { 2 - 7 } & background & buffer & impact & background & buffer & impact \\
\hline Melandrium album & $55.2 \pm 7.4$ & $10.1 \pm 2.0$ & $8.8 \pm 2.0$ & $1.11 \pm 0.08$ & $1.42 \pm 0.13$ & $0.12 \pm 0.04$ \\
\hline Stellaria media & $60.0 \pm 32.6$ & $25.6 \pm 3.0$ & $4.0 \pm 0.9$ & $0.72 \pm 0.07$ & $0.47 \pm 0.06$ & $0.05 \pm 0.01$ \\
\hline Urtica dioica & $29.7 \pm 2.9$ & $13.0 \pm 1.8$ & $8.7 \pm 1.6$ & $0.60 \pm 0.15$ & $0.60 \pm 0.17$ & $0.45 \pm 0.25$ \\
\hline Rumex confertus & $9.4 \pm 2.9$ & $8.7 \pm 2.4$ & $1.9 \pm 0.6$ & $0.60 \pm 0.20$ & $0.79 \pm 0.27$ & $0.03 \pm 0.01$ \\
\hline Arctium tomentosum & $15.8 \pm 4.6$ & $3.9 \pm 0.4$ & $1.2 \pm 0.5$ & $0.37 \pm 0.12$ & $0.09 \pm 0.04$ & $0.17 \pm 0.11$ \\
\hline Cirsium setosum & $31.5 \pm 12.4$ & - & $7.7 \pm 1.7$ & - & - & $0.30 \pm 0.13$ \\
\hline Achillea millefolium & $14.9 \pm 6.9$ & $3.0 \pm 0.5$ & $5.1 \pm 3.5$ & $2.19 \pm 1.20$ & $0.16 \pm 0.02$ & $0.95 \pm 0.31$ \\
\hline Tanacetum vulgare & $37.0 \pm 13.0$ & $9.6 \pm 2.1$ & $7.6 \pm 1.4$ & $0.15 \pm 0.03$ & $0.17 \pm 0.03$ & $0.31 \pm 0.08$ \\
\hline Artemisia vulgaris & $6.8 \pm 3.8$ & $3.0 \pm 2.7$ & $5.0 \pm 1.1$ & $0.14 \pm 0.02$ & $0.16 \pm 0.06$ & $0.06 \pm 0.01$ \\
\hline Leonurus quinquelobatus & $18.6 \pm 2.7$ & $3.7 \pm 1.8$ & $1.2 \pm 0.2$ & $0.09 \pm 0.01$ & $0.10 \pm 0.00$ & $0.016 \pm 0.004$ \\
\hline Pulmonaria mollissima & $38.0 \pm 0.4$ & - & $25.2 \pm 1.8$ & $1.90 \pm 0.20$ & - & $0.91 \pm 0.06$ \\
\hline Plantago major & $55.6 \pm 60.5$ & 6.7 & $10.4 \pm 3.1$ & $5.90 \pm 1.20$ & $0.6 \pm 0.01$ & $2.2 \pm 1.30$ \\
\hline Mean \pm Error of mean & $33.5 \pm 6.1$ & $8.7 \pm 2.5$ & $7.2 \pm 2.4$ & $1.35 \pm 0.58$ & $0.46 \pm 0.13$ & $0.46 \pm 0.24$ \\
\hline
\end{tabular}

species is observed, and characteristic plant communities play a significant role. Species diversity is very high, which is associated with low anthropogenic impact. After the accident remediation work was carried out on sites of abandoned settlements. Such locations were overgrown with the usual for this area nitrophilous vegetation. It remains at these sites until now.

To summarize the data on the effect of chronic exposure to herbaceous plants, we compared the seed progeny of EURT coenopopulations with background samples for a number of key indicators, using $F$-test with significance level $p<0.05$ and the lower and upper bound of the $95 \%$ confidence intervals for $C I$. Table 2 shows that the survival rate of germinating seeds in the early stages of ontogeny in most species from the EURT area was not significantly different from background samples, or was reduced. Growth rates (the rate of formation of true leaves and root length), which characterize the safety of the apical meristems, the rate of cell division, effectively assess the ability of germinating seeds to the further development. In samples of seeds from the contaminated area, these characteristics were in most cases lower than in the background samples. With respect to rate of leaf formation, suppressive effect was observed in germinating seeds of 22 coenopopulations, and the length of the roots - in 13 out of 32 studied coenopopulations in EURT area. Only the root length of germinating seeds in the Rumex confertus from the impact zone was greater than in those from background coenopopulation. We failed to assess the effects of growth criteria in the Urtica dioica because the germinating seeds did not survive until the end of the experiment.

Among all the species listed in Table 2 special attention should be given to the Taraxacum officinale and Plantago major, because their populations from EURT zone showed all the variety of effects. This is due to the fact that studies conducted over several years. For example, the dandelion from the buffer zone for 14 years twice showed the effect of hormesis, within 3 years the quality of the seeds from this sample was very low, while in other years no differences between coenopopulations were found. The seed progeny of the plantain from impact cenopopulation demonstrated an increased radioresistance on growth parameters twice within a six-year cycle of research.

For ecological point of view the important conclusion is that all species studied should be characterized by the range extension of individual variability in 2-3 times for all viability indicators. Estimation of mutability based on the frequency of morphose occurrence showed that mutation process in various plant species under conditions of prolonged exposure is more intense than in the background populations. A portion of the damage was hidden and appeared only after additional irradiation. We found no definite relationship between the seed progeny mutability and intensity of chronic exposure of maternal plants in all studied species (nonlinear effects). 


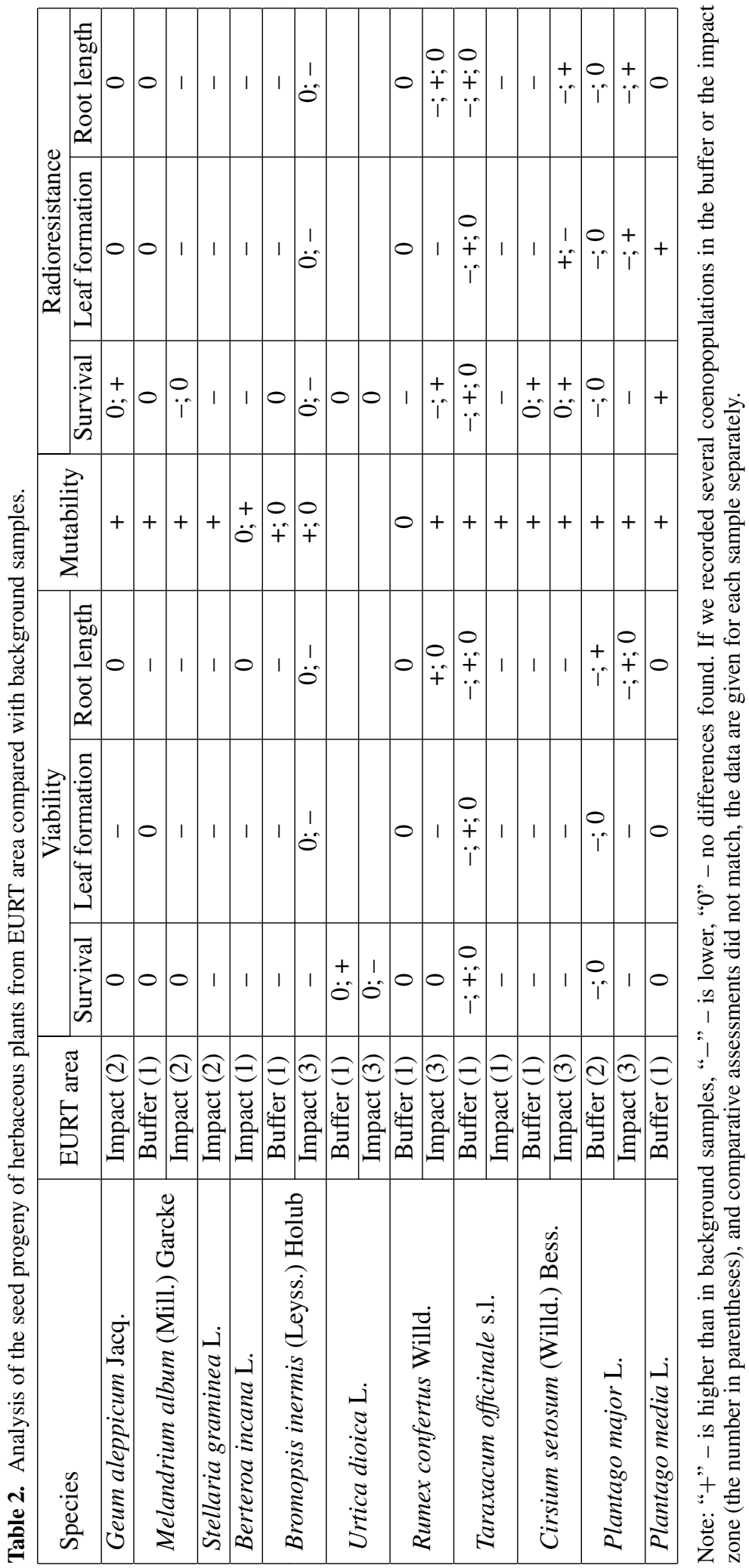




\section{CONCLUSION}

Thus, current levels of soil contamination near the epicenter of the accident reach $30 \times 10^{3} \mathrm{kBq} / \mathrm{m}^{2}$ for ${ }^{90} \mathrm{Sr}$ and $1 \times 10^{3} \mathrm{kBq} / \mathrm{m}^{2}$ for ${ }^{137} \mathrm{Cs}$. Contamination levels are reduced in accordance with a power function with increasing distance from the accident site and at a distance of more than $100 \mathrm{~km}$ become close to background values. The same dependence is characteristic for accumulative ability of plants growing in a wide range of soil contamination levels. In the EURT area there was a significant reduction in TF values compared with the background values.

In the EURT impact area vegetation is a complex of synanthropic and semi-natural plant communities in various stages of degradation and restoration successions. Species diversity of forest and meadow coenoses is very high, and contribution of ruderal species is decreased, due to low anthropogenic load. Importantly, the current state of phytocenosises on the sites of the demolished local villages is largely determined by the degree of human impact in the pre-accident period, and remediation activities.

Our data to assess the reproductive potential of coenopopulations suggest that for most species the viability of their seed progeny, formed in a gradient of radioactive contamination, are either not different from background samples, or reduced half a century after the accident. Mutability of seed progeny in impact coenopopulations in all studied species was high. Radioadaptation phenomenon, i.e. increased resistance to provocative irradiation was rare and unstable.

\section{Acknowledgments}

This study was completed with support by the Russian Foundation for Basic Research (project no. 11-04-01260), the Interdisciplinary Projects of the Ural Division of the Russian Academy of Sciences (no. 09-M-24-2001) and the Program for Development of Science and Education Centers (contract no. 02.740.11.0279).

\section{References}

[1] Aarkrog A., Dahlgaard H., Nielsen S.P. et al. Radioactive inventories from the Kyshtym and Karachay accidents: estimates based on soil samples collected in the South Urals (1990-1995) // The Science of the Total Environment, 1997. Vol. 201. P. 137-154.

[2] Pozolotina V.N., Molchanova I.V., Karavaeva E.N., Mikhaylovskaya L.N., Antonova E.V. Radionuclides in terrestrial ecosystems of the zone of Kyshtym accident in the Urals // J. of Envirom. Radioact. Vol. 101. 2010. P. 438-442.

[3] Molchanova I., Pozolotina V., Karavaeva E., Mikhaylovskaya L., Antonova E. and Antonov K. Radioactive inventories within the East-Ural radioactive state reserve on the Southern Urals // Radioprotection. 2009. Vol. 44. No 5. P. 747-757.

[4] Zheleznov A.V., Zheleznova N.B., Smetanin N.I., and Sukhanovskaya V.S. Intrapopulation Variability of Some Meadow Plant Species in Respect of Their Ability to Accumulate ${ }^{90} \mathrm{Sr} / /$ Russian Journal of Genetics 2002, Vol. 38, Number 5, Pages 521-525

[5] Karavaeva E.N., Mikhaylovskaya L.N., Molchanova I.V., Pozolotina V.N. The ${ }^{90} \mathrm{Sr}$ and ${ }^{137} \mathrm{Cs}$ accumulation by herbs from soils contaminated as result the operation of Nuclear fuel plants // The problems of biogeochemistry and geochemical ecology, 2010, no 1 (12), pp. 85-90. 